\title{
Coronary heart disease and water hardness in Scotland-is there a relationship?
}

\author{
W C S SMITH AND I K CROMBIE \\ From the Cardiovascular Epidemiology Unit, Ninewells Hospital and Medical School, Dundee DDI 9SY
}

SUMMARY Scotland has a mortality rate from coronary disease which is one of the highest in the world. There is also a considerable variation in this mortality rate within Scotland. Data on water hardness throughout Scotland have been collected from Regional Water Authorities to see whether variations in coronary mortality rates can be explained by variations in water hardness. Analysis demonstrates a much weaker negative association than has been demonstrated in studies in other countries. The geographical variation in coronary mortality rates in Scotland cannot be explained by variations in water hardness, and weak association between these in Scotland is discussed.

Scotland has one of the highest mortality rates from coronary heart disease in the world. Within Scotland there is considerable geographical variation in coronary mortality rates. ${ }^{1}$ A number of studies have demonstrated a negative association between coronary heart disease rates and water hardness, $\mathrm{eg}^{23}$. In this study we have examined the relation between coronary heart disease mortality rates and total water hardness in the 56 Scottish local government districts to see whether the geographical variation in disease can be explained by variations in water hardness.

\section{Methods and results}

Standardised mortality ratios (SMR) for coronary heart disease (International Classification of Diseases, Rubrics 410-414) were calculated for men aged 35 to 64 years for each of the 56 local government districts in Scotland. Deaths for the years 1979-83 were pooled and the SMRs were calculated using the central year, 1981 , population estimates. The geographical pattern of coronary heart disease SMRs is complex and has been described. ${ }^{1}$

Data on total water hardness for each of the 56 districts were obtained from the Departments of Water Services of the Scottish Regional Councils. The data obtained were the annual mean total hardness in milligrams per litre from the routine chemical analysis of principal water supplies for the year 1983. In a few districts the same data for an adjacent year were used. These values were then weighted by the size of population supplied to produce a weighted mean annual value for total hardness for each local authority district. The values thus derived were then compared with the data collected by the Water Research Centre for 22 towns in Scotland and were found to be similar.

The coronary heart disease SMRs have been plotted against the weighted mean total hardness values for each of the 56 districts in Scotland (figure). The correlation coefficient between the SMRs and water hardness was $-0 \cdot 17$. To allow for possible nonnormality of the data a suitable transformation (log) of water hardness was taken and a similar result was obtained $(r=-0 \cdot 24)$. Allowance for the difference in

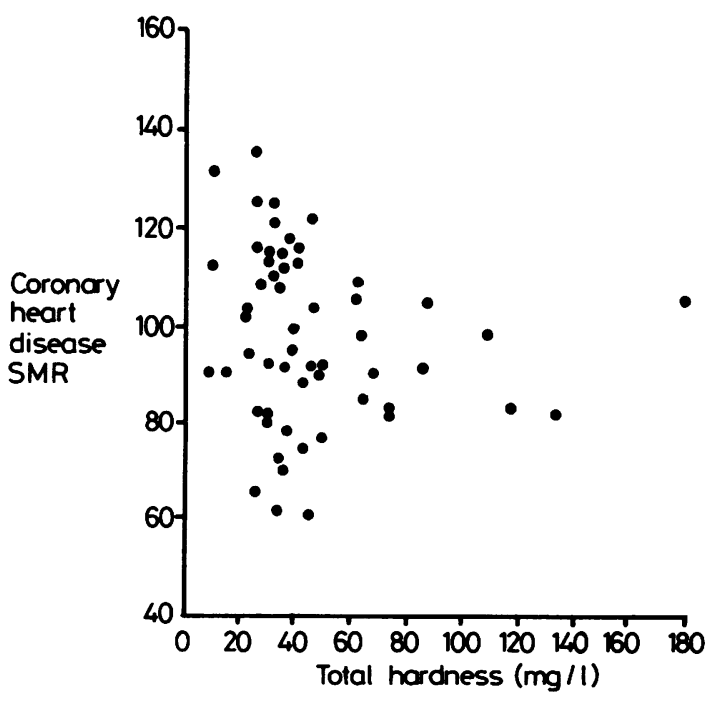

Relationship between coronary heart disease and water hardness in the 56 Scottish districts. 
variability of the SMRs among the districts by the appropriate weighted regression ${ }^{4}$ did not alter this conclusion.

\section{Discussion}

Previous studies of heart disease and water hardness have revealed a strong negative correlation. The British Regional Heart Study found a correlation of $-0.67^{2}$ and a study of 15 centres in Europe $-0.48^{3}$ whereas the results of this similar study in Scotland show a much weaker correlation. These studies had a wide range of total hardness values (greater than $300 \mathrm{mg} / \mathrm{l})$ whereas the range in Scotland is much narrower, 52 out of the 56 districts having less than $100 \mathrm{mg} / \mathrm{l}$. However, the study of Pocock et al ${ }^{2}$ suggests that the water hardness effect occurs in the range 0-150 mg/l so that some effect would be expected in the Scottish data. The negative direction of the relationship is in agreement with the other studies.

The geographical variation in coronary heart disease mortality in Scotland cannot be adequately explained by variations in water hardness. However the negative relationship is consistent with other work. Alternative explanations of the geographical variations in disease must be explored, and the
Scottish Heart Health Study has been undertaken to collect risk factor information in 22 local government districts to address this question. ${ }^{5}$

We thank the Departments of Water Services of the Regional Councils in Scotland for providing the water quality data and R F Lacey, of the Water Research Centre, Marlow, Bucks, for allowing us to compare the results from his work.

\section{References}

${ }^{1}$ Crombie IK, Smith WCS, Kenicer MB, Tunstall Pedoe HD. Geographical variation in coronary heart disease mortality in Scotland. Health Bulletin 1986; 44: 193-202.

2 Pocock SJ, Shaper AG, Cook DG, et al. British Regional Heart Study: geographic variations in cardiovascular mortality, and the role of water quality. Br MedJ 1980; 1: 1243-9.

${ }^{3}$ Masironi R, Pisa Z, Clayton D. Myocardial infarction and water hardness in the WHO myocardial registry network. Bull WHO 1979; 57: 291-9.

${ }^{4}$ Pocock SJ, Cook DG, Beresford SAA. Regression of area mortality rates on explanatory variables: what weighting is appropriate? Appl Statist 1981; 30: 286-95.

${ }^{5}$ Smith WCS, Crombie IK, Irving JM, Kenicer MB, Tunstall Pedoe HD, Tavendale R. The Scottish Heart Health Study. Eur Heart J 1985; 6(Suppl 1): 105. 